\title{
“动定轉化递进說”与“多旋廻論” 之爭及碚証法
}

\author{
张 曾 淯
}

陈国达教授的“动定轉化递进說”与黄汲 清教授的“多旋迴論”之爭，是近年来我国大 地构造学科范帱內的一場具有哚远意义的学 术爭諭。它是从討論中国东部大地构造的性 貭开始的。陈氏訩为：中国东部地区在中生 代以后重新出現高度活动性的事实，表明地 壳发展已进入了一个新的历史阶段。他訩为 地壳发展以如下不可逆的形式递进轉化 ${ }^{[1,2]}$ :

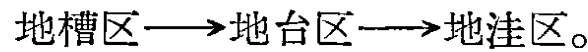

黃氏則否訓“地洼”的存在，訩为这仅能 表明此类地台的后期构造旋迴特別显著而 已，他把这种活动性較大的地台称为 “准地 台”，以区別于稳定性較大的 “正地台”。我 且訩为地壳基本构造单元只能有地槽及地台 两种，然而它們之間可以互相轉化 ${ }^{[3]}$ :

$$
\begin{aligned}
& \text { 地槽 } \stackrel{\text { 㯖化 }}{\longrightarrow} \text { 地台 } \\
& \text { 地台 } \stackrel{\text { 再生 }}{\longrightarrow} \text { 地槽 }
\end{aligned}
$$

在两位教授的理論中，不但引用了大量 的科学事实, 乎且力图以唯物讋証法来論証 各自的覌点, 这是值得学习的一种优良学 风，有助于把我国大地构造研究推向新的高 峯。笔者閱讀了两位教授的有关論著, 得益 匪浅。对他們的学术見解，因学疏識线，不
拟安加評論。但对双方論文中运用讋証法部 分，覚得頗有可以商榷之处，特提出来向同 志們, 特別是黃、陈两位地稹学界前輩請教。

\section{一 “动定轉化递进說”在总体上 符合于而証发展規律}

陈氏訩为: “地洼的出現，体現出地壳 发展是不断前进的过程，是螺旋状上升而不 是循环的过程, 也就是活动区与稳定区两个 对立面之間不断斗爭，辯証地互相轉化更 替, 依照 ‘否定之否定” 法則演变和发展, 从 簡单的形式到复杂形式，由低級到高級阶段 的过程" ${ }^{[2]}$ 。

但黄氏則䚯为陈氏的論点否訩矛盾和矛 盾的同一性 ${ }^{[3]}$ 。黃氏的稹疑可以表达如下: “活动地带与稳定地带的矛盾是地壳中諸种 矛盾的綜合表現，这种矛盾与地壳的形成是 共存的,”因为 “只有矛盾的两方面才能互相 轉化，而轉化也只有 “各向其相反方面” ”, 所以 “活动地带只能向稳定地带轉化，稳定 地带只能向着活动地带轉化,”如果說能轉向 “既不同于地槽又不同于地台的“第三种基本 构造单元一一地洼区”，那末 “难道作为一 种“基本构造单元”的“地洼区”，就可以沒有 对立面而单独存在嗎?”所以陈国达是“把地 
壳发展中本来是同时共存又是对立統一的两 个方面分割开来”，也就是 “实际上否詰矛 盾，否訩矛盾的同一性”。

笔者訓为，㣴氏的这些評語在覌点与方 法上均有可以考虑之处。应該提出的有:

（1）地台能否轉化为“地洼”，固待科学 上进一步研究, 不必过早定論。但就哲学意 义視之，說地台轉化成既非地槽又非地台的 “地洼”，是否意味违反了讋証法呢? 答复应 是否定的。恩格斯說: “不断的变化, 郎抽 象和自身的同一性之拋弃，在所謂无机界也 是存在的。地貭学就是这种不断变化的历 史”[4]。如果說地槽 $\rightarrow$ 地台 $\rightarrow$ 地洼的发展过 程是否訩了矛盾，那又如何去理解生物发展 以至社会发展的过程呢? 甚至黄氏所一再強 調的“多旋迴”也变得难于理解了，因为造成 后期旋迴不同于前期旋迴的新生作用，难道 不也正是事物向前发展而不同于既往的产物 嗎？黃氏既然訩为多旋迴覌点符合于不断革 命論与革命阶段論 ${ }^{[3]}$ ，为何不能以同样的覌 点去理解“动定轉化递进說”呢?

（2）黃氏对毛主席的“矛盾論”中关于同 一性的那段話，显然也作了过于机械的理 解。正因为如此，他得出了陈氏論点否訩矛 盾的結論。毛主席的原話是很清楚的: “第 一，事物发展过程中的每一种矛盾的两个方 面，各以和它对立着的方面为自己存在的前 提，双方共处一个統一体中；第二，矛盾着 的双方，依据一定的条件，各向其相反方面 轉化。这些就是所謂同一性”[5]。如果深入 思考，特別反复鉆砶“矛盾論”的全文，黃氏 的說法就不无疑問：1. 毛主席在該段中所說 的只是每一种矛盾的两个方面具有同一性, 共处于一个統一体中。但在复杂的事物的发 展过程中，是有一对以上的矛盾共同存在，
所以也就会有不同矛盾的各个方面。“矛盾 諭” 例举了不少这方面的例子。而在陈氏的 理論中，地槽与地台的对立、地台与地洼的 对立, 正是二个不同发展阶段的矛盾, 故仍 各有其对立面存在, 而分別隶属于不同的統 一体之中，所以是得不出“否䚯同一性”的結 論的。倒是黃氏把事物发展过程中的矛盾看 得过于簡单, 似乎只有一对, 因此地台只能 与地槽相互对立, 自然也就容不得“地洼”的 存在了。2. 黄氏对“轉化”的理解也欠安当, 他似乎詮为轉化只能是轉化为对方自身, 因 此地槽只能变成地台, 而地台又只能变为地 槽。事实上，哲学上所謂的轉化，并不只是 簡单地指轉化为对方自身，更重要的是指轉 化后具备对方所具有的某些特点。因此，地 槽与地台的矛盾, 使地台轉化为与地槽有某 些共同恃点一一高度活动性的 “地洼”。而 这，也正符合于“否定之否定”这一事物发展 規律的。

（3）陈氏虽訜为“地洼”眬不同于地台, 也不同于地槽, 却从未訩为“地洼”皖非稳定 地带又非活动地带。相反, 他正是将“地洼” 看成是活动地带的一种。按笔者的理解, 陈 氏的原意是：活动地带与稳定地带只是反映 了运动的差別性与相对性, 也郎是表明了构 造单元的基本性貭; 而地槽、地台、“地洼”則 是构造单元的基本型式。因此地槽与“地洼” 各以其基本性貭師活动性与地台的基本性貭 郎稳定性相互对立、相互轉化。这里也根本 得不出陈氏否訩矛盾的結論。倒是黃氏在有 意或无意之中违反了邏輯規律，也就是在推 諭过程中更換了概念。他似乎訩为：稳定地 带只有地台一种, 而活动地带只有地槽一 种，因此如果說“地洼”躴非地台文非地槽， 也就等于說既不是稳定地带, 又不是活动地 
带。这样自然会得出相反的結論。

陈氏的理論总的說来虽符合于唯物讋証 法，但是，缺乏进一步說明各种构造型式的 具体轉化条件与內因, 因而难免使人感到抽 象而不易理解。在矛盾双方的相互轉化中， 条件是很重要的, 不然就不能透彻地說明轉 化的必然性。毛主席說: “矛盾着的对立的 双方互相斗学的結果；无不在一定条件下互 相轉化。在这里, 条件是重要的。没有一定 的条件，斗学着的双方都不会轉化”[6]。所 以看来这正是陈教授的理論在今后应使之完 善的地方。

\section{二“多旋迴論”也含有端証 唯物主义的因素}

黃氏訜为其論点符合于讋証法，因为它 表明了“地壳形成后，就在活动地带与稳定 地带互相依存、互相轉化中向前发展。” ${ }^{3[}$ 抽 象地說, 升无非議之处。但重要的䦓題是, 他在研究具体的变化过程中, 主要着重了事 物的量变或簡单的稹变 (周而复始的机械式 运动), 因而在总体上, 有时就不㷛流露一 些形而上学的色彩。尽管如此, 却不能由此 而訩为黃氏論点毫无辯証因素可言。所以象 陈氏那样，过分地貶低“多旋呬”的意义，䚯 为它 “只統計了地壳运动的次数, 而沒有分 析說明其原因……只罗列了某些构造单元在 地壳发展过程中的某些表面現象, 而沒有触 及不同发展阶段地壳运动的本稹”[2]; “把該 处地壳发展过程看作仅仅是数量上的变化, 仅仅是重复几个造山旋迴而已” ${ }^{[7]}$, 以及象 許善明同志那样，甚至訩为多旋迴只是 “一 个空洞抽象的构造术語而已”[9]，也都是值 得商榷的。应該提出的有:

（1）陈氏重視地壳发展的稹变，这是正
确的。但如果因此而訩为量变沒有价值, 則 是不妥当的。按讋証法的理解, 事物的量与 稹是有机地結合在一起的, 量总是表現为一 定貭的量, 决沒有超越稹的量存在; 貭也总 是体現为一定量的稹, 决沒有脫离量的稹存 在。所以, 其中一方的变化必然会引起另一 方的变化。也就是說, 量变与稹变是讋証的 統一，两者不能截然分开。恩格斯說: “由 量到稹的轉变 = “禿械的”宇宙覌, 量的变化 改变着稹”[4]，就是这个意思。何况在“多旋 迴”理論中，也利非毫无触及貭变，每一构 造旋迴之間，显然存在着稹的区別。黃氏不 足之处在于：他虽然触及了构造旋迴間的部 分稹变, 却沒有进一步探索由之可能引起的 构造单元的根本性稹变, 或者仅是把根本性 的稹变覙为机械式的可逆回复而已。

（2）陈氏要求黄氏分析說明地壳运动的 原因与本稹, 在原則上也未始不可。但如果 訩为描述、統計地壳运动的次数沒有意义, 或者操之过急, 訩为可以避开描述、統計, 而逕自研究地壳运动的本稹, 那就很可能产 生脫离实际的傾向, 也就是說容易因此而违 反讋証唯物主义的䚯識諭。应該看到：描 迹、統計乃是分析、說明問題原因与本稹的 一种必要手段，沒有前者，后者也就变成不 可能或不可靠的了。毛主席在“实践論”中指 出: “訩識的过程, 第一步, 是开始接触外 界事情, 属于感覚阶段。第二步, 是綜合感 覚的材料加以整理和改造, 属于概念、判断 和推理的阶段。只有感覚的材料十分丰富 (不是零碎不全)和合于实际(不是錯覚)，才 能根据这样的材料造出正确的概念和諭理 来。” 又說: “理性的东西所以靠得住, 正是 由于它来源于感性, 否則理性的东西就成了 无源之水，无本之木，而只是主覌自生的靠 
不住的东西了”[9]。由此可見，表面現象 及 片面材料虽非本稹的东西，但却是䛊識事物 的根据。只有这种材料占有得愈多愈丰富, 才有可能去粗取精、由表及里得出更樑刻和 更完全的反映事物本稹的东西。所以“多旋 迴”也絕不是空洞抽象的构造术語, 而有其 具体而实在的內容的。

黃氏的理諭，尽管在总体上有一些弱 点, 但在很多具体問題上作了比較深入細致 的探索，特別在对立面的轉化条件及原因方 面, 提出了比較丰富的科学論証, 因而易于 为人們所接受。这是必須加以肯定的, 因为 它具有相对的真理性。

\section{三“动定轉化递进說”与 “多㯀迴”諭的相互补充}

关于这两个論点相互排斥方面, 前人已 經談得很多。这里要提出的是, 象科学史上 一切相互对立的理論一样，它們还具有相互 补充的一面，这也是符合于事物的矛盾法則 的。

首先两位教授的諭点虽有不同，但却都 攅弃了早先比較流行的不可逆的地槽 $\rightarrow$ 地台 說。該說不但与地球內能目前仍处于継續积 聚的新覌点相违，而且也与若干地区的构造 发展史不符。而就其哲学思想来說，不外是 变相的运动熄灭論。

其次，不論“地洼”也好，“准地台”也 好, 問題的提出都是基于这样的一个事实:

師中国东部在中生代后确实重新出現了高度 的活动性, 无法以传統的地台定义加以概括; 而其所具的活动性特点，也确实不同于地 槽。关于这一点，陈、黃两位是沒有分岐 的。試比輘“地洼”的特征和“准地台”后期的 特征, 无論在岩相、构造运动、岩浆活动以
至抅陷形状都有相似之处。

現在問題爭論的实稹主要是在于: 究竟 以另立一个构浩阶段——“地洼”較为合适? 还是另創一种地台的变种——“准地台”为 好? 这并不以人們的意志为轉移, 而有如下 两項标准: 1. 何者更真实地反映了客观实 际；2. 何者更符合于辯証法。实际上, 此两 者没有也不应該有矛盾的。因为反映客覌实 际的真正科学里, 必然貫穿着辯証法; 反言 之，辯証法如不和唯物主义相結合，也就很 易变为“詭讋术”。所以对研究者来說, 重要 的問題仍然是在唯物讋証法的指导下，深入 呼究已积累的实际資料与初步結論。也就是 列宁所說的: “对具体事物作具体分析”。黃、 陈两位已为这一爭論开辟了道路, 也就为进 一步研究創造了条件。

笔者粗浅的看法是, 既然爭論双方都是 为了解决同一課題, 而彼此又都包含有相对 的真理在內, 那末, 把两者的合理部分加以 結合，将有利于問題的解决。笔者无意調和 两者的矛盾，而是訩为：“动定轉化递进說” 不足之处，看来正可以用“多旋迴論”的論点 加以补充，而后者也不必完全排斥前者。例 如, 黃氏之䚯为 “准地台” 所以不同于 “正地 台”, 乃是由于基底㖶化一般較低。那末, 基 底 (郎陈氏的“第一构造层”) 僵化的高低不 也可以补充于“递进說”中，用以部分地說明 不同地台轉化为“地洼”何以有先后快慢的原 因嗎!

长期、反复作用的地壳动力, 对刚度較 小的地稹体,結果是使其增加刚度而僵化; 而 对已偪化的, 則有可能使其通过断裂而重新 获得活动性。金属材料試驗表明，延性材料 可因塑变而硬化，強度增高，延性減低；而 当反复受力时, 总的趋向是降低強度而加速 
断裂的发生。当然, 地稹体較金属材料远为 复杂，不能乎論，但总的规律是一致的。因 此，地槽的多旋迴运动，可使其偠化而变成 地台; 而地台的多旋迴运动, 可使其重新活 动而成“地洼”，由于这种新的活动性是通过 基底䉼裂而发生的，因而“地洼”区常以断裂 构造发育为其特色之一。胡朝元䚿为块断运 动是中国中生代后地壳运动的特点 ${ }^{[10]}$, 也部 分地說明了这一点。因此可以䚿为, 多旋迴 运动是地壳运动的量的表現, 而构造型式的 递进轉化是地壳运动的貭的体現, 前者是动 力, 后者是結果, 两者是相依相存、相反相 成的。
以上仅是笔者不成熟的看法, 謹望大家 批評指正。

[1] 陈国达, 科学通报, 1959 年第 3 期。

[2]陈国达, 地盾学报, 40 卷, 第 2 期, 1960。

[3] 黄波清、姜春发, 地稹学报, 42 卷, 第 2 期, 1962 。

[4] 恩格斯, 自然辯証法 (中譯本)，176-177 頁，人 民出版礼。

[5]毛泽东，矛盾論，人民出版社。

[6] 毛泽东, 关于正确处理人民內部矛盾的問題, 人民 出版邧。

[7]陈国达, 科学通报, 1960 年第 17 期。

[8] 䚺善明, 科学通报, 1961 年第9期。

[9] 毛泽东, 实践論, 人民出版社。

[10] 胡朝元, 地盾論評, 18 卷, 第 4 期, 1958 。

\title{
多相渗流研究的近况和展望
}

\author{
郭劣平 刘慈絠 李永善 楊緒强 孙敏荣
}

（中国科学院兰州地盾研究所）

渗流力学是現代流体力学的一个分枝, 它是研究流体在孔隙介盾中运动規律的学 科。渗流力学也是多种工程技术的重要理諭 基础, 諸如石油和天然气开采、土壤改良和 水利工程、地下水的开发和人工儲气庫、水 文地稹和水文勘探、鉄道工程及煤矿开采， 甚至化工、陶瓷、治金等工程技术，无一不 与渗流力学有密切关系。此外, 在国防尖端 技术中，已出現一些特殊渗流力学問題。

与渗流力学有关的孔隙介頁的主要特征
一般是：渗流通道的截面极小( 約为 $10^{-8}$ 厘米 ${ }^{2}$ ); 內部比面极大 (約为 $10^{4}$ 来)。因此, 毛細管作用显著，渗流阻力很大，渗流速度 很小，以至慣性力常可忽略不計。这些特点 使渗流力学与一般的流体力学明显地区別开 来。

自从法国工程师达西于 1856 年发現渗 流基本定律, 正式揭开渗流力学的历史之 后，百余年来，特別是近 30-40 年，渗流 力学特別是其中的多相渗流得到相当迅速的 